\title{
PADRÕES DE SEGREGAÇÃO ESCOLAR NO BRASIL: UM ESTUDO COMPARATIVO ENTRE CAPITAIS DO PAÍS
}

\author{
Marcio da Costa* \\ Tiago Lisboa Bartholo ${ }^{*}$
}

\begin{abstract}
RESUMO: $\mathrm{O}$ artigo analisa padróes de segregação escolar em quatro grandes cidades do Brasil: Belo Horizonte, Curitiba, Rio de Janeiro e Sáo Paulo. Os dados foram fornecidos pelo Inep e apresentam informaçôes para alunos matriculados no primeiro segmento do ensino fundamental entre 2007 e 2010 . Utiliza o Índice de Segregação (Segregation Index) e considera duas características dos alunos: 1) cor; 2) distorção idade-série. Resultados preliminares sugerem que: 1) a cidade de Curitiba apresenta os maiores níveis de segregaçáo escolar e Rio de Janeiro os menores; 2) a inclusão das matrículas do ensino privado aumenta os níveis de segregação escolar e seu impacto é maior nos anos mais recentes (2009-2010); 3) há uma associação entre as regras de matrícula nas cidades e os padróes de segregação escolar.
\end{abstract}

Palavras-chave: Segregação Escolar. Oportunidades educacionais. Alistamento escolar. Desigualdade educacional.

\section{SCHOOL SEGREGATION PATTERNS IN BRAZIL: A COMPARATIVE STUDY AMONG THE COUNTRY'S CAPITALS}

ABSTRACT: The paper analyses patterns of school segregation in four big cities in Brazil: Belo Horizonte, Curitiba, Rio de Janeiro and São Paulo. Data was provided by INEP and present information concerning pupils enrolled in the first segment of primary education (1st to 5th grade) from 2007 to 2010. Segregation was assessed using the Segregation Index, according to two indicators of potentially disadvantaged pupils: 1) colour (black pupils); 2) age/grade distortion. Preliminary results suggest that: 1) Curitiba presents the highest levels of school segregation and Rio de Janeiro the lowest; 2) when data from private schools are included, the segregation levels in all cities rise and its impact appears to be higher in recent years (2009 and 2010); 3) there is an association between enrolment regulations and patterns of school segregation.

Keywords: School Segregation. Educational Opportunities. School Enrolment. Educational Inequality.

* Universidade Federal do Rio de Janeiro, Faculdade de Educação e coordenador do Observatório Educaçăo e Cidade, Rio de Janeiro, RJ, Brasil. E-mail de contato: marcioc@pobox.com.

** Universidade Federal do Rio de Janeiro, Colégio de Aplicação, Rio de Janeiro, RJ, Brasil. E-mail de contato: tiagobartholo@gmail.com. 


\title{
LES MODÈLES DE SÉGRÉGATION SCOLAIRE AU BRÉSIL: UNE ÉTUDE COMPARATIVE ENTRE QUELQUES VILLES-CAPITALES DU PAYS
}

\begin{abstract}
RÉSUMÉ: L'article analyse les schémas de ségrégation scolaire dans quatre grandes villes du Brésil: Belo Horizonte, Curitiba, Rio de Janeiro et São Paulo. Les données ont été fournies par l'INEP et elles présentent l'information aux élèves inscrits dans le premier segment de l'école élémentaire (les cinq prémières années d'études) entre 2007-2010. Nous utilisons l'indice de ségrégation, selon deux indicateurs d'elèves potentiellement défavorisés: 1) couleur (élèves noirs); 2) distorsion âge / année scolaire. Les résultats préliminaires suggèrent que: 1) à Curitiba on constate les plus hauts niveaux de ségrégation scolaire par contre à Rio de Janeiro ils en sont les plus bas; 2) l'inclusion des écoles privées augmente les niveaux de ségrégation scolaire et son impact est plus important au cours des dernières années (2009-2010); 3) il y a une relation entre les règles d'inscriptions dans les villes et la ségrégation scolaire.
\end{abstract}

Mots-clés: La ségrégation scolaire. Les possibilités d'éducation. Le taux de scolarisation. Inégalités scolaires.

\section{Introdução}

egregação escolar é um termo que vem lentamente se disseminando no ambiente acadêmico brasileiro. O conceito de segregação tem seu significado bastante próximo daquele adquirido na linguagem cotidiana. Como está no Dicionário Aurélio: "tratamento desigual ou injusto dado a uma pessoa ou grupo, com base em preconceitos de alguma ordem, notadamente sexual, religioso, étnico, etc." ${ }^{1}$ Na ideia de segregação escolar, está implícita a percepção de que há algo de injusto na agregação de estudantes em agrupamentos escolares e que a desigualdade de oportunidades se manifesta no âmbito escolar. Não há, contudo, no tratamento acadêmico dado ao conceito, inevitabilidade de que segregação seja decorrente de algum processo deliberado, intencionalmente dedicado a promover restriçóes a algum grupo social específico. Frequentemente, a segregação, conforme será exposto na operacionalização do conceito, está associada a dimensôes territoriais, de local de residência.

Esse artigo se dedica a reportar achados sobre a segregação escolar brasileira, usando marcadores reconhecidos de características associadas com condições de desvantagem na sociedade, a partir de informaçóes disponíveis no Censo Escolar brasileiro. A proposta geral é, portanto, observar padróes de segregação escolar em grandes cidades de áreas metropolitanas, ao longo de um período curto de tempo. Essas diferentes cidades apresentam processos de alistamento escolar variáveis e padrōes de segregação social e urbana igualmente distintos. Apesar da conotação negativa do termo segregação, a abordagem aqui adotada não parte do 
princípio que agrupamentos escolares tendencialmente homogêneos são intrinsecamente negativos. Tratamos o assunto descritivamente, reconhecendo que há problemas potenciais associados ao fenômeno - do ponto de vista da igualdade de oportunidades, mas a intenção é fornecer evidências que ajudem a reconhecer e compreender sua ocorrência. Julgamentos e discussôes de políticas precisam ser informados.

O conceito de segregação escolar aqui adotado refere-se a uma distribuição desigual de indivíduos portadores de uma determinada característica de presumida desvantagem social, por entre um conjunto de escolas, que podem ser tomadas como espaços de oportunidades educacionais distintas. Seria de todo improvável que houvesse distribuição perfeitamente homogênea de estudantes com qualquer característica distintiva - por um conjunto numeroso de escolas. Assim, as análises aqui desenvolvidas são operacionalizadas com referência a um padrão hipotético perfeitamente igualitário, mas com baixíssima probabilidade de ser encontrado em situações reais. Esse padrão-ouro permite comparar as medidas de segregação em diferentes momentos e áreas geográficas. Designamos "desvantagem potencial" a características que podem ser resumidas em uma variável e que expressam condiçóes, reconhecidas na pesquisa educacional, com forte associação a desvantagens no desempenho e no rendimento escolar.

O tema da segregação está diretamente ligado à temática da qualidade e equidade dos sistemas educacionais e, de forma mais ampla, à justiça social. Evidências de diferentes países, incluindo o Brasil, sugerem que concentrar alunos com características específicas em determinadas escolas pode influenciar a forma como eles são tratados, a qualidade do ensino e a aspiração para os níveis subsequentes de educação. Há ainda indicaçôes de que sistemas educacionais mais segregados ou com políticas que, intencionalmente, agrupam alunos em desvantagem potencial possuem maior associação entre os níveis de aprendizagem e o perfil socioeconômico dos alunos, ou seja, alunos com perfil socioeconômico mais desfavorável apresentam desempenho inferior. (HAAHR et al., 2005; EUROPEAN GROUP..., 2005; JENKS et al., 1972; BRITO; COSTA, 2010; BARTHOLO, 2014)

\section{Antecedentes}

A discussão sobre segregação escolar remonta a um tempo histórico relativamente curto e recente, mas de intensas disputas e mudanças acentuadas nos padrôes de distribuição de oportunidades escolares, bem como conflitos e mudanças ainda maiores nos arranjos sociais afetados por avanços da mentalidade igualitária que tende a prevalecer no mundo ocidental contemporâneo. Um marco 
importante de tal processo pode ser registrado na célebre querela norte-americana identificada como Brown vs Board of Education, em meados dos anos $1950 .^{2}$

Após a Segunda Guerra Mundial, o resultado militar do conflito expressa não apenas a supremacia militar de uma grande aliança internacional, mas, também, a vitória moral de valores igualitários, confrontados com o talvez mais longevo e resistente princípio discricionário presente na humanidade: a noção de raça e das hierarquias naturais a ela associadas.

Como evento marcante de um longo conflito civilizacional, a tendência igualitarista recrudesce com força no pós-guerra, alimentando novos ou revigorando já existentes movimentos por direitos iguais e oportunidades menos sujeitas a caracteres adscritos. Brown vs. Board of Education integra um conjunto de movimentos que eclodem alguns anos mais tarde sob diferentes formas, como nas lutas de libertaçáo colonial, no feminismo, nos Black Panthers ou nos nascentes movimentos contra a discriminação por opção sexual. São também marcos desse tempo o impacto global da revolução cubana e da revolução cultural chinesa, os movimentos hippies e a contracultura em geral, o Concílio Vaticano II, ou as grandes mobilizações envolvendo, sobretudo, jovens, mas com apelos sociopolíticos mais abrangentes, que marcam uma guinada naqueles anos de grande florescimento, inclusive no campo econômico.

Nesse contexto de virada cultural, política, tecnológica (a corrida estimulada pela Guerra Fria e pelo aumento do consumo) e econômica, a educação é objeto de esperanças, atençôes e disputas intensas. Ainda que náo necessariamente com essa denominaçáo, a questáo da segregaçáo ocupa lugar de destaque na agenda política referente à educação. Outro marco importante, ainda norte-americano, foi o relatório Equality of Educational Opportunity, mais conhecido como Relatório Coleman. Por encomenda do Congresso daquele país, um estudo específico sobre a distribuiçáo de oportunidades educacionais mobilizou grandes esforços e recursos em busca de padróes de desigualdade na oferta escolar que permitisse compreender - e combater - a então considerada principal fonte da desigualdade social em geral.

Pode-se especular que, derrotada a matriz civilizacional que preconiza hierarquias sociais derivadas de atributos naturais, diante da constatação da permanência de uma estrutura social pouco móvel - ou menos móvel do que se desejaria - em contextos de acentuado desenvolvimento econômico e modernização geral, seja compreensível a condução do debate sobre as oportunidades educacionais, ao centro da agenda.

Segregação escolar deriva diretamente da preocupação com a desigual distribuição de oportunidades. Todavia, nos marcos do Relatório Coleman, muito menos que a desigualdade na oferta escolar, as características culturais dos públicos escolares devem ser tomadas como fontes principais das diferenças observadas no 
desempenho e trajetória escolar de grupos sociais e étnicos distintos. Tomando-o como referência, políticas de intenção equalizadora - destaque para o Head Start e o Title I - são desencadeadas, adotando modelos de educação compensatória. Tais medidas visavam, basicamente, reconhecer que diferenças raciais estão associadas a recursos culturais e econômicos distintos, e adotar a concentração de investimentos nos ambientes com ampla proporção de indivíduos em desvantagem nesses campos. Tais políticas lidam com o fenômeno da segregação racial, fortemente demarcada territorialmente, mas não podem ser consideradas dessegregadoras.

Outro tipo de iniciativa provocou muito mais reaçóes, inclusive violentas, naquele contexto, principalmente ao longo dos anos 1970. Geralmente forçadas por determinaçóes judiciais, com origem em Brown vs. Board of Education, as chamadas políticas de busing, de deslocamento obrigatório de estudantes com vistas a alterar a composição racial de escolas de diversas cidades, suscitaram reaçóes acaloradas e contribuíram decisivamente para que a questáo da segregação tivesse destaque na agenda educacional. Essas podem ser consideradas políticas que buscavam forçar, nos espaços escolares, uma integração de difícil obtenção nas demais esferas da vida.

Os achados de Coleman e sua equipe, em parte, retomam uma abordagem já manifesta na década anterior, em fins dos anos 1950. Forquin (1995) resenha essas abordagens que propóem uma interpretação cultural para as diferenças de mobilidade social, decorrentes de diferenças de escolarização. Simplificadamente, alunos provenientes de meios menos modernos estariam menos aptos a usufruir das oportunidades descortinadas pela ampliação da escolarização, desde que seus valores mais distantes do individualismo ascético não se ajustariam bem aos processos escolares. Políticas compensatórias - antecipação da escolarização, por exemplo - poderiam reduzir tais diferenças, ao custo de concentrar recursos nos espaços com alta proporção de estudantes em condiçôes de desvantagem potencial.

Políticas compensatórias e dessegregadoras foram sempre alvo de críticas de diversas origens, que podem ser classificadas de morais/políticas ou operacionais. As críticas de cunho político/moral podem ser resenhadas em duas vertentes. A primeira reage à distribuição compensatória de recursos, acusando seu caráter supostamente antirrepublicano, ou mesmo apelando à noção das diferenças individuais como fonte da impossibilidade de um igualitarismo pleno. A segunda vertente pode ser resumida na crítica aos programas compensatórios como uma forma de camuflagem da natureza intrinsecamente iníqua das sociedades capitalistas. Para essa concepção, muito desenvolvida e parcamente aqui resumida, programas com tal intenção seriam mais amortecedores, promotores de ilusóes, do que verdadeiramente distribuidores de oportunidades com maior equidade. A própria noção de igualdade ou integração entre grupos sociais distintos seriam meros artifícios ideológicos com função de acomodação diante de uma realidade que não poderia ser transformada nos marcos do sistema econômico dominante. 
Do ponto de vista operacional, ainda que menos conhecido no Brasil, provêm críticas talvez mais contundentes. Enquanto as críticas que denominamos, genericamente, políticas/morais se estabelecem em um terreno filosófico, ensaístico, aquelas emanadas de ambientes acadêmicos mais aparelhados teórica e cientificamente, encetam duros golpes nas políticas dedicadas a mitigar os fenômenos da segregação. Não se trata, aqui, de apenas questionar princípios, mas de investigar efeitos. Dessa forma, aspectos afeitos às chamadas consequências não intencionais ganham destaque, ao lado de denúncias importantes sobre a inconsistência de tais iniciativas. Teorias como a desigualdade maximamente mantida (MMI - maximally maintained inequality) e sua sucedânea teoria da desigualdade efetivamente mantida (EMI - effectivelly maintained inequality) (LUCAS, 2001), ou ainda a teoria da fila, de Thurow (1977), em alguma medida traduzem em indicadores sofisticados a percepção da frustração dos esforços equalizantes presentes em iniciativas educacionais. Programas específicos são igualmente escrutinados, como o Head Start ou No Child Left Behind, e afirma-se com frequência sua incapacidade de proporcionar redução efetiva na desigualdade. (MADAUS et ali, 2008)

$\mathrm{Na}$ sociologia da educação em seus tempos heroicos, fundacionais, podem ser encontrados elementos em meio aos quais nos debatemos, até hoje, quanto à associação entre desigualdade e educaçáo, ainda que não estejamos nos mesmos pontos. Houve avanços relevantes e, parece, algumas polêmicas foram superadas. Ainda que sobrevivam nos meios mais rudimentares concepçóes do tipo "quanto pior, melhor", esse discurso dificilmente será encontrado presentemente na academia.

O grande avanço oriundo do campo da sociologia escolar, nomeado "eficácia escolar", é tributário das questóes levantadas no Relatório Coleman e seus correlatos, desenvolvidos em outros países. Neste movimento, a busca e achado de novas evidências que revalorizam o trabalho escolar e as expectativas sobre ele depositadas, descortina novos campos para a investigação educacional, mas suscita também ajustes e novas controvérsias. A questáo da segregação - latente em estudos e políticas dos anos 1960 - ressurge revigorada pelas contribuiçóes da sociologia urbana e por avanços técnicos agregados por esta. Por outro lado, aspectos na fronteira da sociologia com a pedagogia, reacendem a discussão sobre as formas de agrupamento escolar, na temática dos grupos de habilidade (ability grouping). (IRESON; HALLAM, 2001)

No caso brasileiro, pode-se observar o adensamento dos estudos sobre eficácia escolar, em meio ao clamor pela elevação da qualidade educacional, revelada como muito insatisfatória, a partir da produção de vários indicadores referentes ao desempenho de estudantes. Não se observa, contudo, grande interesse na questão da segregação escolar. Esta dimensão analítica, que guarda destaque no cenário internacional, pode promover contrapontos a algumas assunçóes referentes ao 
conceito de eficácia e a sua operacionalização, à medida que enfatiza aspectos de equidade diante da questão da qualidade.

\section{Métodos e hipóteses}

$\mathrm{O}$ artigo apresenta dados fornecidos pelo Instituto Nacional de Estudos e Pesquisa Educacional (Inep) para todas as escolas, públicas e privadas, em quatro capitais brasileiras de 2007 a 2010: Belo Horizonte, Curitiba, Rio de Janeiro e São Paulo. O Índice de Segregação (Segregation Index - GS) foi utilizado considerando dois indicadores de desvantagem potencial disponíveis, amplamente reconhecidos, por se correlacionarem com o desempenho dos alunos: a) cor; b) distorção idade-série.

Nesse artigo, segregação é definida como a distribuição desigual de alunos em desvantagem potencial em um conjunto de escolas. Gorard (2009) destaca quatro propriedades desejáveis que índices de segregaçáo escolar devem apresentar, em especial, em estudos com desenho longitudinal.

[...] 1) invariante organizacional, de tal forma que se uma escola é dividida em duas, ou se duas escolas se fundem, com a mesma proporção de $\mathrm{FSM}^{3}$ em todas, então o valor do índice permanece o mesmo; 2) invariante por tamanho ou escala, de forma que se o número de estudantes FSM e não-FSM é multiplicado por uma constante em todas as escolas, o valor do índice permanece inalterado; 3) invariante composicional, de forma que se o número de alunos FSM é multiplicado por uma constante em todas as escolas, o valor do índice permanece o mesmo e; 4) afetado por transferências, de maneira que se um aluno FSM troca de uma escola com mais alunos FSM para outra com menos, o valor do índice diminui [...]. (GORARD, 2009, p. 644)

A invariância composicional (compositionally invariant) é chave para pesquisadores interessados em medir padróes de segregação ao longo dos anos. É fundamental que os valores indicados pelo índice náo se alterem pela provável mudança no número total de alunos em desvantagem potencial em uma determinada região. Há um extenso debate internacional sobre quais indicadores seriam mais apropriados para determinadas questóes de estudo. (GORARD; 2009; 2011; JOHNSTON; JONES, 2011; HARRIS, 2012)

Optamos pelo Índice de Segregação (GS) por apresentar o que Gorard e Taylor (2002) denominaram como uma invariância composicional robusta (strong compositionally invariant), em comparação com outro indicador muito utilizado em pesquisas educacionais, o Índice de Dissimilaridade. (DUNCAN, 1955) 
Ambos os índices medem o mesmo aspecto, mas o GS tem uma interpretação mais direta e simples. (GORARD; TAYLOR, 2002; BARTHOLO, 2013)

O GS indica a proporção exata dos alunos em desvantagem que deveria trocar de escola, de forma que não houvesse qualquer segregação quanto à característica específica expressa no indicador. A fórmula abaixo descreve o GS:

$$
\mathbf{G S}=0.5^{*}\{\Sigma|\mathbf{F i} / \mathbf{F}-\mathbf{T i} / \mathbf{T}|\}
$$

onde:

Fi é o número de alunos em desvantagem potencial na escola "i”, e "i” varia de 1 até o número total de escolas no universo em foco;

F é o número total de alunos em desvantagem potencial do mesmo conjunto de escolas;

Ti é o número de alunos na escola "i”, e "i" varia de 1 até o total de escolas no universo em foco;

T é o total de alunos nas escolas do mesmo conjunto de escolas. (GORARD; TAYLOR; FITZ, 2003)

$\mathrm{O}$ artigo apresenta três modelos complementares. Inicialmente, descreve padrôes de segregação para todos os alunos matriculados no primeiro segmento do ensino fundamental nas escolas públicas, entre 2007 e 2010. Em seguida, incorpora dados da rede privada de ensino, com o objetivo de observar as mudanças nos níveis de segregação em comparação ao primeiro modelo. Partimos da hipótese de que a inclusão de dados da rede privada de ensino irá aumentar substancialmente os níveis de segregação escolar observados. A razão é simples: espera-se que as escolas privadas tenham proporçôes, substantivamente, menores de alunos em condiçōes de desvantagem potencial.

Bartholo (2014) descreveu os padróes de segregação escolar na rede pública municipal do Rio de Janeiro e os resultados iniciais sugerem que, comparados com outras importantes cidades do mundo, os níveis observados são baixos, indicando uma distribuição mais equânime dos alunos em desvantagem potencial. $\mathrm{O}$ autor indicou a ausência de dados da rede privada, algo como $25 \%$ do total de matrículas, como o principal fator para explicar os baixos níveis de segregação. $\mathrm{O}$ presente estudo pretende testar essa hipótese e, adicionalmente, comparar os níveis observados no Rio de Janeiro com outras importantes capitais no Brasil.

O terceiro modelo do estudo calcula os níveis de segregação na rede pública considerando apenas os alunos matriculados no primeiro ano do ensino fundamental. O principal objetivo desse desenho é começar a identificar fatores 
associados aos padróes de segregação observado entre as cidades. A literatura internacional sugere que a regra para a primeira matrícula na rede pública é um dos fatores explicativos dos padrōes de segregação observados. (GORARD; TAYLOR; FITZ 2003)

A cidade do Rio de Janeiro possui um sistema de matrícula que permite aos pais selecionarem qualquer escola da rede pública no momento inicial da matrícula. No entanto, a indicação inicial não garante o acesso à escola de preferência. Situações de sobredemanda podem ocorrer, em especial em escolas de alta reputação. Nesses casos, a falta de uma legislação clara permite que diretores ou outros agentes da burocracia educacional selecionem os alunos. (BRUEL; BARTHOLO, 2012; COSTA; KOSLINSKI, 2008)

Em contrapartida, as cidades de Belo Horizonte, Curitiba e São Paulo apresentam um sistema de matrícula que não permite que familiares indiquem as escolas de sua preferência. A matrícula inicial é feita a partir do endereço residencial da família. (COSTA et. al, 2013) No caso específico da cidade de São Paulo, os responsáveis podem optar também pelo endereço de trabalho ou de algum parente próximo. (CENPEC, 2012) Sistemas que condicionam a matrícula inicial do aluno ao endereço de moradia ou de trabalho dos responsáveis tendem a reproduzir mais fortemente a segregação residencial nas escolas. $\mathrm{O}$ argumento central é que determinadas políticas podem mitigar o principal fator associado à segregação escolar, a saber, a distribuição espacial das famílias pelos diferentes bairros da cidade. (HARRIS, 2012)

A hipótese inicial do artigo indica que os níveis de segregação escolar serão maiores onde a legislação não permite a escolha dos pais. Isto porque o efeito da segregação residencial na composição social das escolas será maior quando comparado com ambientes que permitem as famílias indicarem escolas de sua preferência. Parte-se da premissa que a livre escolha por parte das famílias amplia a chance de mobilidade dos estudantes, tornando o sistema escolar mais misturado.

\section{As bases de dados e suas limitações}

Os dados apresentados no artigo foram fornecidos pelo Inep ${ }^{4}$. Inicialmente, foram selecionadas três variáveis para descrever alunos em desvantagem potencial: condição presumida de pobreza, cor e distorção idade-série. Essas características têm sido utilizadas em estudos internacionais e nacionais sobre o tema da segregação escolar e apresentam associação com o desempenho escolar. (GORARD; SEE, 2013; BARTHOLO, 2014)

O efeito da pobreza sobre o desempenho escolar é um dos temas centrais no campo da educação e da justiça social. Superar a desvantagem educacional 
inicial significa, entre outras coisas, diminuir a distância do desempenho escolar entre os que nasceram na pobreza e o resto da população. Reduzir a pobreza em si é uma das principais metas das democracias ocidentais (incluindo organismos internacionais, como a Unesco) e os sistemas educacionais exercem papel importante nesse desafio.

Nas bases disponibilizadas pelo Inep, há a informação sobre o Número de Identificação Social (NIS), ${ }^{5}$ que permite identificar famílias em provável situação de vulnerabilidade social e que, em tese, são elegíveis para receber benefício de algum programa social do Estado. Trata-se de uma proxy de pobreza, de fato, o único indicador disponível no Censo Escolar que sugere o nível socioeconômico do aluno.

A segunda variável, cor, tem sido utilizada em diversos estudos no Brasil, e em outros países, para compreender desigualdades sociais relacionadas ao acesso ao mercado de trabalho, renda e exposição à violência (VALLE SILVA, 2001) e não apenas à temática das oportunidades educacionais. Essa variável, coletada conforme os valores adotados pelo IBGE, foi recodificada distinguindo os que se declararam pretos (aqui caracterizados como alunos em desvantagem potencial) dos demais alunos.

A última variável, denominada distorção idade-série, compreende informaçôes dos alunos que não seguiram o fluxo escolar regular. Para detectar a distorção idade-série, foram usadas a data de nascimento e a série frequentada. $\mathrm{O}$ grupo em desvantagem potencial - em situação de atraso escolar - é composto por alunos que: a) foram reprovados em alguma série - retençáo; b) abandonaram a escola e retornaram após algum tempo c) ingressaram tardiamente. A variável foi construída a partir dos critérios utilizados pelo próprio Inep para identificar alunos em situação de atraso escolar (exemplo, alunos com oito anos ou mais matriculados no primeiro ano do ensino fundamental).

Um dos principais benefícios do uso de dados secundários é o baixo custo comparado com outros procedimentos que coletam dados primários. Outra vantagem é a possibilidade de utilizar dados para toda a população de estudantes, o que permite análises mais simples sem o uso de generalização estatística. Modelos estatísticos complexos têm a inconveniência de tornar a compreensão dos resultados mais difícil e, consequentemente, menos acessível a uma audiência não acadêmica. Outro ponto atraente no uso de dados secundários é a ampla possibilidade de replicação das análises utilizando diferentes abordagens ou enfoques.

Os benefícios no uso de dados secundários não devem mascarar as limitaçóes de dados coletados por terceiros, muitas vezes por motivos variados (não necessariamente para propósitos de pesquisa). Yorke (2011) destaca quatro grandes desafios no uso desse tipo de dado: 1) qualidade; b) categorização; c) 
limitações (necessária e opcional); d) reformatação. Discutimos brevemente a principal limitação observada nos dados trabalhados no presente artigo: qualidade.

Um problema recorrente observado em grandes bases de dados são informaçōes faltantes, (missing data), para diferentes variáveis. É sempre muito difícil saber se os dados faltantes estáo distribuídos de forma aleatória entre os diferentes alunos e escolas. Isso significa que é difícil descartar o risco de viés nas análises realizadas. (VAUS, 2011)

Os dados analisados no artigo apresentam melhora no registro, diminuição dos dados faltantes, ao longo dos anos. Bartholo (2013; 2014) descreveu padrão semelhante nas bases de dados fornecidas pela rede pública municipal do Rio de Janeiro e identificou que os alunos com dados faltantes apresentavam rendimento inferior em avaliaçóes externas (Prova Rio), comparado com outros com dados completos. No exemplo citado, as análises sugerem que a distribuição dos dados faltantes não era aleatória e qualquer interpretação deveria ser feita considerando essa limitação.

A Tabela 1 apresenta as proporçóes de alunos em desvantagem potencial e as proporçóes de dados faltantes quanto à cor, separados pelas cidades estudadas, discriminando escolas da rede privada e pública de ensino. Os registros sobre a data de nascimento dos alunos são completos e a informação sobre o NIS não permite codificar o que seria um dado ausente. Estamos, portanto, codificando a ausência de informação (dado faltante) como "não beneficiário de programas sociais" do governo. Há risco de subnotificação de casos no banco. Há, porém, o atenuante de ser obrigatório o cadastro do aluno no NIS, para que a família possa receber os benefícios. Assim, o risco maior é de classificarmos como "em condição de pobreza" alunos que já foram inscritos em tais programas, mas não o são mais.

\section{Tabela 1}

Proporção de alunos e desvantagem potencial e dados faltantes por rede escolar, segundo a cidade, 2007 a 2010

\begin{tabular}{|c|c|c|c|c|c|c|c|c|c|c|c|c|c|c|c|c|c|}
\hline & \multirow{2}{*}{\multicolumn{4}{|c|}{ Belo Horizonte }} & \multirow{2}{*}{\multicolumn{4}{|c|}{ Curitiba }} & \multirow{2}{*}{\multicolumn{4}{|c|}{ Rio de Janeiro }} & \multirow{2}{*}{\multicolumn{4}{|c|}{ São Paulo }} \\
\hline & & & & & & & & & & & & & & & & & \\
\hline & & 2007 & 2008 & 2009 & 2010 & 2007 & 2008 & 2009 & 2010 & 2007 & 2008 & 2009 & 2010 & 2007 & 2008 & 2009 & 2010 \\
\hline \multirow{5}{*}{$\begin{array}{l}\text { Escolas } \\
\text { Públicas }\end{array}$} & & 0.05 & 0.05 & 0.06 & 0.07 & 0.01 & 0.01 & 0.01 & 0.01 & 0.12 & 0.11 & 0.11 & 0.11 & 0.04 & 0.04 & .04 & 04 \\
\hline & in & 0.44 & 0.43 & 0.33 & 0.14 & 0.29 & 0.23 & 0.18 & 0.12 & 0.07 & 0.07 & 0.06 & 0.04 & 35 & 26 & 22 & 22 \\
\hline & & 045 & 0.38 & 0.31 & 0.21 & 0.23 & 0.24 & 0.22 & 0.19 & 0.28 & 0.27 & 0.24 & 0.20 & 0.47 & 37 & 26 & 0.13 \\
\hline & & & 0.10 & 0.09 & 0.08 & 0.05 & 0.04 & 0.05 & 0.05 & 0.20 & 0.18 & 0.17 & 0.18 & 0.05 & 05 & 04 & 84 \\
\hline & & & 0.01 & 0. & 0.02 & 0.002 & 0.002 & 0.004 & 0.002 & 0.02 & 0.03 & 0.03 & 0.03 & 0.01 & 01 & .02 & .02 \\
\hline \multirow{3}{*}{$\begin{array}{c}\text { Escolas } \\
\text { Privadas }\end{array}$} & & & & 0. & 0.4 & 0.6 & 0.5 & 0.52 & 0.52 & 0.6 & 0.5 & 0.5 & 0.49 & 0.33 & 0.30 & 0.27 & 0.27 \\
\hline & & & 0.4 & 0.3 & 0.2 & 0.2 & 0.1 & 13 & 0.09 & 0.15 & 0.12 & 0.10 & 0.09 & 0.26 & 0.22 & .17 & 0.11 \\
\hline & orção idade-série & 0.04 & 0.02 & 0.03 & 0.03 & 0.14 & 0.01 & 0.01 & 0.02 & 0.06 & 0.06 & 0.06 & 0.06 & 0.02 & 0.02 & 0.02 & 0.02 \\
\hline
\end{tabular}

É possível observar que em todas as cidades, em ambas as redes de ensino, pública e privada, a qualidade dos dados melhora ao longo dos anos. Isso fica claro ao observar a evolução da proporção de dados faltantes para cor. A queda é 
expressiva e sugere uma melhora nos protocolos de coleta e/ou uma maior familiaridade/aceitação dos respondentes com os procedimentos.

Há também um padrão claro na proporção de dados faltantes comparando as redes públicas e privadas. Em todas as cidades observadas ao longo de todos os anos, a proporção de dados faltantes na rede privada é maior (com exceção do ano de 2007 para a cidade de São Paulo). Isso sugere que as análises que incluem dados da rede privada tendem a apresentar maior risco de viés, com implicação direta no modelo proposto no artigo, que calcula o impacto da inclusão dos alunos matriculados da rede privada nos níveis de segregação observados em cidades brasileiras. A inclusão de casos (alunos) com pior qualidade (maior proporção de dados faltantes), aumenta o risco de viés, e dificulta a conclusão sobre o efeito líquido da segregação escolar considerando apenas a alocação de alunos entre as redes de ensino (pública e privada).

Por fim, ainda em relação à qualidade dos dados, há diferenças importantes quando comparamos as cidades. Rio de Janeiro apresenta $4 \%$ de dados faltantes para cor considerando alunos matriculados na rede pública em 2010 (o menor valor entre as cidades estudadas), enquanto São Paulo apresenta 22\% no mesmo período. Mais uma vez, essa diferença ameaça as análises comparativas.

Conforme esperado, a proporção de alunos em desvantagem potencial varia entre as cidades observadas. Talvez a diferença mais impactante, e que tem relação direta com as redes de ensino, seja a proporção de alunos em distorção idade-série. Rio de Janeiro aparece com 18\% dos alunos matriculados na rede pública nessa condição. Os dados sáo referentes apenas às matrículas no primeiro segmento do ensino fundamental e é provável que esse número seja ainda maior considerando alunos matriculados no segundo segmento. Outras cidades como São Paulo ou Curitiba apresentam valores muito menores considerando alunos em distorção idade-série, respectivamente $4 \%$ e $5 \%$. Esses valores sugerem práticas e resultados bastante distintos entre as redes de ensino. É pouco provável que a explicação para essa diferença esteja apenas relacionada ao perfil do alunado.

As quatro cidades analisadas apresentam renda per capita muito semelhante $^{6}$. Segundo o Censo realizado pelo IBGE em 2010, as diferenças de renda média são mínimas e dificilmente explicariam os números sobre atraso escolar. $\mathrm{O}$ dado parece consistente, pois também na rede privada a defasagem idade-série é bem maior no Rio de Janeiro que nas outras três cidades.

Estudos futuros devem focar na explicação dos resultados escolares observados entre diferentes redes públicas de ensino. A "cultura da repetência" destacada por Ribeiro (1991) pode nos dar algumas pistas sobre os valores destacados nas Tabela 1. Se for verdade que há um componente cultural importante, influenciando os índices de defasagem idade-série, ainda nas séries iniciais da escolaridade obrigatória, essa "cultura da repetência" seria mais forte no Rio de 
Janeiro, impressão reforçada pelo contraste dos índices também na rede privada. Não há elementos aqui para avançar nessa explicação, mas fica uma pista.

A proporção de alunos com NIS na rede pública, considerando os quatro anos analisados, apresenta valores difíceis de interpretar e que, em grande medida, contradizem os valores divulgados regularmente pelo governo federal sobre beneficiários de grandes programas de transferência de renda, como por exemplo, o Bolsa Família. Os dados sugerem uma diminuição na proporção de famílias com NIS ao longo dos anos em todas as cidades. Por exemplo, em São Paulo, a queda é de 47\% em 2007 para 13\% em 2010.

Nesse mesmo período, dados fornecidos pelo Ministério do Desenvolvimento Social indicam que o total de famílias atendidas pelo principal programa de transferência de renda do governo Federal, Programa Bolsa Família, saltou de 11,1 milhóes em 2007 para 12,4 milhóes em 2010.7 Não há nenhuma indicação que os grandes centros urbanos tenham apresentado queda expressiva no número de potenciais beneficiários no mesmo período. Diante da descrição inicial dos dados, optamos por calcular os indicadores de segregaçáo apenas para duas variáveis: cor e distorção idade-série. $\mathrm{O}$ uso dos dados sobre NIS para calcular os indicadores de segregação escolar demandam uma checagem sobre a consistência das informaçóes obtidas nas bases do Inep.

\section{Padrões de segregação escolar em capitais do Brasil}

A Tabela 2 apresenta os valores do Índice de Segregaçáo (GS) para cor, considerando apenas as matrículas na rede pública de ensino, sendo possível observar uma queda nos níveis de segregação escolar para cor em todas as quatro cidades. Para o fato de esse declínio ser constante ao longo dos anos exige atenção, e há três explicaçóes possíveis para o padrão observado. A primeira está ligada a possíveis mudanças na legislação que regula a alocação dos alunos (primeira matrícula e transferências entre escolas) ou outras açôes não mapeadas da burocracia educacional, que estariam tornando os sistemas educacionais menos segregados. A segunda, sugere que a melhora na qualidade dos dados (diminuição da proporção de dados faltantes) pode influenciar o cálculo dos indicadores. A terceira indica que o aumento da proporção de matrículas na rede privada torna a composição social das escolas públicas mais homogênea. Apresentaremos dados neste artigo que corroboram esta explicação. 


\section{Tabela 2}

Índice de Segregação (GS), para cor preta, na rede pública de ensino, primeiro segmento do ensino fundamental (\%)

\begin{tabular}{lcccc}
\hline \multicolumn{1}{c}{ GS Cor } & $\mathbf{2 0 0 7}$ & $\mathbf{2 0 0 8}$ & $\mathbf{2 0 0 9}$ & $\mathbf{2 0 1 0}$ \\
\hline Belo Horizonte & 34 & 26 & 21 & 21 \\
Curitiba & 27,5 & 26,5 & 25 & 25,5 \\
Rio de Janeiro & 18 & 16 & 15,5 & 15,5 \\
São Paulo & 21 & 15 & 14 & 15 \\
\hline
\end{tabular}

Fonte: Instituto Nacional de Estudos e Pesquisa Educacional.

A descrição inicial apresentadas nas tabelas 1 e 2 não sugere uma associação clara entre a melhora da qualidade dos dados (menor proporção de missing) e um aumento da proporção de alunos pretos em pelo menos três cidades: Curitiba, Rio de Janeiro e São Paulo. Nessas cidades, a proporção de alunos pretos se mantém praticamente estável apesar da melhora constante na qualidade dos dados. Minas Gerais apresenta comportamento distinto, que pode indicar viés nos dados faltantes para cor. A diminuição constante dos dados faltantes é acompanhada de um crescimento também constante de alunos pretos. A melhora gradual na qualidade dos dados ao longo dos anos sugere que qualquer comparação entre os níveis de segregação das cidades analisadas deve considerar apenas os dados mais recentes (2009-2010). Nesse caso, os valores indicam que Curitiba e Belo Horizonte apresentam os maiores níveis de segregação escolar para cor.

\section{Tabela 3}

Índice de Segregação (GS) para distorção idade-série na rede pública de ensino - primeiro segmento do ensino fundamental (\%)

\begin{tabular}{lcccc}
\hline \multicolumn{1}{c}{ GS Distorção idade-série } & $\mathbf{2 0 0 7}$ & $\mathbf{2 0 0 8}$ & $\mathbf{2 0 0 9}$ & $\mathbf{2 0 1 0}$ \\
\hline Belo Horizonte & 32 & 27,5 & 25,5 & 23,5 \\
Curitiba & 24,5 & 21,5 & 26 & 26,5 \\
Rio de Janeiro & 19,5 & 19 & 18,5 & 17 \\
São Paulo & 22 & 21,5 & 22,5 & 23,5 \\
\hline
\end{tabular}

Fonte: Instituto Nacional de Estudos e Pesquisa Educacional.

A Tabela 3 apresenta os valores do GS para distorção idade-série. Os dados para essa variável apresentam qualidade estável ao longo dos anos sem nenhum dado faltante. Os resultados sugerem padróes distintos quando comparamos as cidades. Belo Horizonte apresenta um declínio forte e constante ao longo dos anos. Rio de Janeiro também revela um declínio, porém de forma mais suave. As outras duas cidades, Curitiba e São Paulo, sugerem uma estabilidade dos níveis 
de segregação ao longo dos anos, com pequenos aumentos e declínios nos anos investigados.

Uma comparação inicial dos níveis de segregação escolar nas redes públicas nas cidades selecionadas (utilizando apenas dados de 2009 e 2010) indicam alguns padróes, que devem ser interpretados com cautela. Não esqueçamos que há sempre a ameaça dos dados faltantes afetarem o resultado final. Portanto, utilizaremos apenas as informaçôes de 2010, supostamente de melhor qualidade, para compararmos segregação escolar entre redes públicas. Curitiba apresenta maiores níveis de segregação para ambas as variáveis, cor $(25,5 \%)$ e distorção idade-série $(26,5 \%)$, enquanto Rio de Janeiro apresenta os menores níveis também para ambas as variáveis - $15,5 \%$ para cor e $17 \%$ para distorção idade-série.

Esse resultado parece corroborar a hipótese inicial que sugere que sistemas com livre escolha dos pais apresentariam menores níveis de segregação escolar. Devemos considerar, contudo, que os níveis de segregação escolar são afetados por muitos fatores, incluindo fatores externos às redes de ensino. $\mathrm{O}$ mais notório e possivelmente com maior impacto nos indicadores é a segregação residencial. (HARRIS, 2011) Estudos futuros devem apresentar modelos mais sofisticados, que levem em conta a moradia dos alunos, para identificar o efeito líquido de políticas educacionais e/ou ações da burocracia educacional nos padrões de segregação descritos. ${ }^{8}$

O segundo modelo do artigo analisa o impacto da incorporação de alunos da rede privada nos níveis de segregação escolar nas cidades selecionadas. Recalculamos os indicadores de segregaçáo incluindo todos os alunos matriculados no primeiro segmento do ensino fundamental. Em seguida, comparamos os valores do GS considerando apenas as matrículas na rede pública com os cálculos que consideram os alunos matriculados em ambas as redes, pública e privada.

\section{Tabela 4}

Incremento no GS para cor e distorção idade-série pela inclusão dos alunos da rede privada de ensino por cidade, segundo o ano

\begin{tabular}{lcccc|cccc}
\hline & \multicolumn{4}{c|}{ GS Cor (incremento \%) } & \multicolumn{3}{c}{$\begin{array}{c}\text { GS distorção idade- } \\
\text { série (incremento \%) }\end{array}$} \\
\hline \multicolumn{1}{c}{ Cidade } & $\mathbf{2 0 0 7}$ & $\mathbf{2 0 0 8}$ & $\mathbf{2 0 0 9}$ & $\mathbf{2 0 1 0}$ & $\mathbf{2 0 0 7}$ & $\mathbf{2 0 0 8}$ & $\mathbf{2 0 0 9}$ & $\mathbf{2 0 1 0}$ \\
Belo Horizonte & 15 & 27 & 33 & 38 & 11 & 18 & 22 & 23 \\
Curitiba & 16 & 26 & 34 & 20 & 63 & 28 & 23 & 30 \\
Rio de Janeiro & 28 & 59 & 64 & 61 & 31 & 39 & 41 & 44 \\
São Paulo & 28 & 50 & 53 & 50 & 27 & 28 & 29 & 26 \\
\hline
\end{tabular}

Fonte: Instituto Nacional de Estudos e Pesquisa Educacional. 
A Tabela 4 apresenta os percentuais relativos de incremento no GS a partir da inclusão de alunos de escolas privadas nas análises, considerando os dois indicadores de desvantagem potencial. Os resultados foram calculados segundo a fórmula abaixo, onde:

GSpp é o GS calculado considerando alunos matriculados nas escolas públicas e privadas;

GSp é o GS calculado apenas considerando alunos da rede pública.

\section{$\{$ GSpp - GSp $\} /$ GSp}

Os dados confirmam que há uma diferença na composição social das escolas da rede pública e privada. A inclusão de alunos da rede privada nos cálculos do GS torna o sistema de ensino mais segregado, ou seja, a distribuição de alunos em desvantagem potencial fica mais desigual. As medidas apresentadas mostram com clareza que a hipótese inicial foi corroborada, no entanto, é preciso sublinhar que, em muitos casos, o aumento proporcional relativo foi modesto (principalmente para distorção idade-série), indicando que a inclusão de alunos da rede privada não tornou o sistema escolar muito mais desigual.

Um ponto que chama atenção é um padrão observado em todas as cidades para a variável cor, que indica um impacto maior no aumento proporcional relativo do GS em anos mais recentes (2009-2010). Isso sugere que as diferenças na composição social e alocação de alunos entre os sistemas público e privado se acentuaram em 2009 e 2010 em comparação com 2007 e 2008. Se compararmos 2007 com 2010 é possível afirmar que, considerando todas as matrículas no ensino fundamental, a segregaçáo escolar aumentou nas cidades analisadas e esse aumento pode estar relacionado, em grande parte, à migração de alunos da rede pública para a privada. Ou, em outras palavras, o impacto da incorporação de alunos da rede privada na segregação escolar é significativamente maior em 2010. Como explicar esse resultado?

Uma possível explicaçáo é o aumento da proporção de matrículas na rede privada observada em muitas cidades brasileiras, incluindo as quatro estudadas. Esse aumento pode ser um reflexo da melhora da renda da populaçáo no mesmo período, o que permite um aumento dos gastos familiares com educaçáo, em meio a uma percepçáo cristalizada sobre a baixa qualidade do ensino na rede pública. A Tabela 5 apresenta a evoluçáo das matrículas na rede privada no primeiro segmento do ensino fundamental entre 2007 e 2010. 


\section{Tabela 5}

Proporção de alunos matriculados no primeiro segmento do ensino fundamental da rede privada, período 2007 a 2010

\begin{tabular}{lcccc}
\hline \multicolumn{1}{c}{ Rede Privada } & $\mathbf{2 0 0 7}$ & $\mathbf{2 0 0 8}$ & $\mathbf{2 0 0 9}$ & $\mathbf{2 0 1 0}$ \\
\hline Belo Horizonte & 18,8 & 20,4 & 22,3 & 23,3 \\
Curitiba & 18 & 18,5 & 21,3 & 23,1 \\
Rio de Janeiro & 18,1 & 26,5 & 27,5 & 28,6 \\
São Paulo & 19,5 & 21,3 & 22,6 & 24,3 \\
\hline
\end{tabular}

Fonte: Instituto Nacional de Estudos e Pesquisa Educacional.

É razoável presumir que essa migração de estudantes não seja aleatória. Nesse caso, famílias com melhores condiçóes financeiras teriam maiores condiçóes de optar pela rede privada de ensino. É plausível que essa migração ao longo dos anos explique o aumento do impacto (aumento proporcional relativo) da incorporação de alunos da rede privada na segregação escolar. Por outro lado, esse resultado também ajuda a entender os padróes do GS calculados considerando apenas alunos matriculados na rede pública (ver Tabelas 2 e 3). Em poucas palavras, o aumento no número de matrículas na rede privada torna a população que frequenta a escola pública mais homogênea, aumentando a chance de tornar o sistema público menos segregado, mas contribuindo para tornar o sistema educacional, como um todo, mais segregado.

O último modelo do artigo calcula os índices de segregação considerando apenas alunos da rede pública matriculados no primeiro ano do ensino fundamental. O principal objetivo desse modelo é especular sobre fatores associados aos padróes de segregação observados. As regras para a primeira matrícula na rede pública diferem entre as cidades analisadas e a literatura internacional e nacional sugere que as regras para a alocação de alunos nas escolas, a primeira matrícula ou as transferências ao longo do processo de escolarização, são um dos fatores explicativos dos padróes de segregação. (GORARD; TAYLOR; FITZ 2003; BARTHOLO; COSTA, 2014; BARTHOLO, 2014) A matrícula de ingresso no ensino fundamental é destacada em nosso estudo, porque presume-se que, nessa faixa etária, dois condicionantes operam com mais força: a menor autonomia de deslocamento das crianças e o poder da burocracia escolar de cumprir as regras de alocação de alunos.

A hipótese inicial do estudo foi corroborada pelos resultados das Tabelas 2 e 3: cidades que permitem que as famílias escolham as escolas de sua preferência apresentam menores níveis de segregação, comparado com cidades que atrelam a matrícula do aluno ao endereço de residência das famílias. $\mathrm{O}$ último modelo permite verificar se, na primeira matrícula obrigatória, esses constrangimentos se manifestam mais intensamente. 


\section{Tabela 6}

Índice de Segregação (GS) para cor na rede pública de ensino primeiro ano do ensino fundamental (\%)

\begin{tabular}{lcccc}
\hline \multicolumn{1}{c}{ GS Cor } & $\mathbf{2 0 0 7}$ & $\mathbf{2 0 0 8}$ & $\mathbf{2 0 0 9}$ & $\mathbf{2 0 1 0}$ \\
\hline Belo Horizonte & 30,5 & 25 & 23 & 29 \\
Curitiba & 41,5 & 41 & 37 & 40 \\
Rio de Janeiro & 21 & 21,5 & 20 & 19,5 \\
São Paulo & 21 & 21 & 22,5 & 27 \\
\hline
\end{tabular}

Fonte: Instituto Nacional de Estudos e Pesquisa Educacional.

A Tabela 6 apresenta os dados para todas as cidades para a variável cor. A distorção idade-série não foi incluída nessa análise, porque apresenta proporção muito baixa de alunos nessa faixa etária.

Em todas as cidades, o índice de segregação é mais elevado no primeiro ano escolar, do que no primeiro segmento como um todo. No entanto, o padrão que chama atenção é o aumento proporcional mais robusto nas cidades com regras de matrícula que não permitem a escolha dos pais. Considerando apenas os valores do ano de 2010, temos as seguintes diferenças proporcionais relativas entre o índice de segregação calculado apenas para alunos matriculados no primeiro ano e o total de alunos no pimeiro segmento: Belo Horizonte (+38\%), Curitiba (+57\%), Rio de Janeiro (+26\%) e Sáo Paulo (+80\%). Os dados iniciais corroboram a hipótese de que os constrangimentos atuam mais fortemente sobre crianças menores e, possivelmente, sobre pais com menor conhecimento das redes e de seus "atalhos".

$\mathrm{O}$ modelo apresenta fragilidades. Por exemplo, não controla fatores territoriais, e é uma primeira abordagem para compreender o papel da legislação educacional nos padróes de segregação escolar entre capitais no Brasil. Estudos posteriores devem apresentar outros desenhos que busquem isolar (melhorar a qualidade da inferência causal) os efeitos de políticas específicas.

\section{Conclusão}

O artigo compara dados sobre a distribuição de alunos em desvantagem potencial em escolas públicas e privadas de quatro capitais no Brasil. Evidências de diferentes países sugerem que a segregação escolar é um fenômeno universal, que deve ser considerado como consequência de fatores como a segregação residencial, políticas educacionais e escolha parental. Esses fatores, por sua vez, são reconhecidamente correlacionados com o que se denomina isolamento social, econômico e cultural. (HARRIS, 2011) 
Os dados iniciais sugerem níveis distintos de segregação entre as cidades, porém com alguns padrōes definidos sobre a evolução dos indicadores ao longo dos anos. As análises têm caráter mais descritivo, e próximos trabalhos devem permitir medir o efeito líquido de políticas educacionais na segregação escolar.

Chama atenção a melhora na qualidade dos dados ao longo do período analisado e o fato de a rede pública apresentar uma menor proporção de dados faltantes comparado com as matrículas na rede privada. Lamentamos náo ter sido possível usar o único indicador de nível socioeconômico presente no Censo Escolar, o que permitiria introduzir maior densidade nas análises.

Destacamos três principais resultados obtidos nesse estudo. $\mathrm{O}$ primeiro é a comparação dos níveis de segregação escolar entre grandes capitais no Brasil. A descrição inicial sugere que a cidade de Curitiba apresenta os maiores níveis de segregação escolar, considerando apenas matrículas na rede pública para cor e distorção idade-série. Por outro lado, Rio de Janeiro apresenta os menores níveis considerando as mesmas variáveis.

A incorporação de matrículas da rede privada sugere um aumento nos níveis de segregação em todas as cidades para todas as variáveis. A segregação escolar entre as redes de ensino (pública e privada) parece aumentar ao longo do período analisado. Uma possível explicação é o aumento na proporção de alunos matriculados na rede privada, o que poderia estar tornando o sistema escolar, como um todo, mais segregado. Isso explicaria também o declínio observado nos níveis de segregação escolar para cor, considerando apenas matrículas na rede pública.

Por fim, os dados descritos no terceiro modelo do artigo sugerem uma associação entre os níveis de segregação escolar e as regras que regulam a primeira matrícula na rede pública no ensino fundamental. Aparentemente, a possibilidade/ impossibilidade de escolher uma escola longe do seu endereço de residência pode estar afetando os padróes de segregaçáo escolar descritos em grandes cidades no Brasil, conforme já relatado na literatura internacional. Resta, seguindo essa trilha, desenvolvermos estudos que apontem efeitos da segregação escolar no Brasil sobre outros aspectos da vida escolar e social.

Como apontado no início, esse é um artigo com pretensóes mais descritivas e pequeno alcance analítico. Trabalhou, porém, sobre bases de dados pouco exploradas quanto a análises no nível dos alunos, posto que somente após 2007 os dados do censo educacional brasileiro passam a trazer informaçóes individualizadas. Esperamos contribuir para maior conhecimento tanto das possibilidades analíticas disponíveis, quanto para o aprofundamento da temática da segregação escolar, fortemente ancorada na questão da desigualdade de oportunidades sociais. 


\section{Notas}

1. Disponível em http://www.dicionariodoaurelio.com/segregacao.

2. Disponível em http://www.uscourts.gov/educational-resources/get-involved/federal-court-activities/brown-board-education-re-enactment/history.aspx.

3. Nos estudos de Gorard e em vários outros, na Grã-Bretanha, o FSM (Free School Meal), ou alimentação escolar gratuita, é a melhor variável, registrada no nível individual, usada como proxy de status socioeconômico. Ela registra as condiçóes de elegibilidade do estudante para receber o benefício.

4. Agradecemos ao Inep pelo acesso a algumas informaçóes individuais, mediante protocolo de confidencialidade, que permitiram operar análises aqui apresentadas.

5. "O Cadastro Único para Programas Sociais do Governo Federal, instituído pelo Decreto n. 6.135/07, é um instrumento de identificação e caracterização socioeconômica das famílias brasileiras de baixa renda, entendidas prioritariamente como aquelas cuja renda per capita mensal é de até meio salário mínimo. Famílias com renda superior (até três salários mínimos) também podem ser cadastradas, para o planejamento ou implementação de programas sociais específicos. Dessa forma, o número de famílias cadastradas é maior que a quantidade de famílias beneficiadas pelo PBF." Disponível em http://www.mds.gov.br/falemds/perguntas-frequentes/bolsa-familia/cadastro-unico/ beneficiario/cadunico-inclusao.

6. Disponível em http://pt.wikipedia.org/wiki/Lista_de_munic\%C3\%ADpios_do_Brasil_por_ renda_per_capita.

7. Disponível em http://www.brasil.gov.br/cidadania-e-justica/2012/10/bolsa-familia-completa-nove-anos-e-beneficia-13-7-milhoes-de-familias.

8. Bartholo e Costa (2014) e Bartholo (2014) analisaram respectivamente o impacto da alocação de alunos por turnos escolares e as transferências de alunos entre as escolas nos níveis de segregação. Os estudos demonstram que a burocracia educacional tem papel ativo na segregação escolar.

\section{Referências}

BARTHOLO, T. L. Measuring between-School Segregation in an Open Enrolment System: The Case of Rio de Janeiro. Journal of School Choice, n. 7, p. 353-371, 2013. Disponível em: <http://www.tandfonline.com/toc/wjsc20/current\#.VNsw_nF-So>. Acesso em: 7 Set. 2013.

. Segregação Escolar na Rede Municipal do Rio de Janeiro: Causas e Consequências. 2014. 341f. Tese de Doutorado. Programa de Pós-Graduação em Educação - Universidade Federal do Rio de Janeiro, 2014.

BARTHOLO, T. L.; COSTA, M. Turnos e segregação escolar: discutindo as desigualdades escolares. Cadernos de Pesquisa, Sáo Paulo, v. 44, n. 153, p. 670-892, 2014.

BRITO, M. S. T.; COSTA, M. Práticas e percepções docentes e suas relações com o prestígio e clima escolar das escolas públicas do município do Rio de Janeiro. Revista Brasileira de Educação, Rio de Janeiro, v. 15, n. 45, p. 500-510, 2010.

COSTA, M. et all. Oportunidades e escolhas: famílias e escolas em um sistema escolar desigual. In: NOGUEIRA; ZAGO; ROMANELLI. (Orgs.). Família \& Escola: novas perspectivas de análise. Petrópolis: Vozes, 2013, p. 131-164. 
EUROPEAN GROUP FOR RESEARCH ON EQUITY IN EDUCATIONAL SYSTEMS. Equity in European Educational Systems: a set of indicators. European Educational Research Journal, v. 4, n. 2, p. 1-151, 2005.

FORQUIN, J. C. Abordagem Sociológica do Sucesso e do Fracasso Escolares. In: FORQUIN, J. C. (Org.). Sociologia da Educação - dez anos de pesquisa. Petrópolis: Vozes, 1995.

HAAHR, J. H. et al. Explaining student performance: evidence from the international PISA, TIMSS and PIRLS surveys. Danish Technological Institute, 2005. Disponível em http://www.danishtechnology.dk. Acesso em: 10/01/2012.

HARRIS, R. Local Indices of Segregation with Application to Social Segregation between London's Secondary Schools. Environment and Planning, v. 44, p. 669-687, 2012.

GORARD, S. Measuring Segregation - Be aware of the cautionary tale by Johnston and Jones. Environment and Planning, v. 43, p. 1-7, 2011.

GORARD, S. Does the index of segregation matter? The composition of secondary schools in England since 1996. British Educational Research Journal, v. 35, n. 4, p. 639-652, 2009.

GORARD, S.; TAYLOR, C.; FITZ, J. Schools, Markets and Choice Policies. London: Routledge Falmer, 2003.

GORARD, S.; SEE, B. H. Overcoming Disadvantage in Education. London: Routledge Falmer, 2013.

JENCKS, C. Inequality: a reassessment of the effect of family and schooling in America. London: Lowe \& Brydone, 1972.

JOHNSTON R, JONES, K. Measuring segregation “a cautionary tale”. Environment and Planning, v. 42, p: 1264-1270, 2010.

MADAUS, G. F., AIRASIAN, P. W. e KELLAGHAN, T. Estudos Empíricos. In: BROOKE, N.; SOARES, J. F. (Org.). Pesquisa em Eficácia Escolar - origem e trajetórias. Belo Horizonte: Ed. UFMG, 2008.

THUROW, L. C. Education and Economic Equality. In: KARABEL; HALSEY. (Orgs.). Power and Ideology in Education. Oxford University Press, 1977.

YORKE, M. Analysing existing datasets: some considerations arising from practical experience. International Journal of Research \& Method in Education, v. 34, n. 3, p. 255-267, 2011.

IRESON, J. HALLAM, S. Ability Grouping in Education. London: Paul Chapman Publishing, 2001.

VALLE SILVA, N. A Research note on the cost of not being white in Brazil. Studies in Comparative International Development, California, v. 35, Summer, p. 18-27, 2001.

Recebido em 30 de dezembro de 2014.

Aprovado em 27 de fevereiro de 2015. 